\title{
Fármacos, plantas medicinais e alimentos e o farmacêutico nesse contexto
}

\author{
Drugs, herbal medicines and food ... \\ and the Pharmacist in the middle
}

Dâmaris SILVEIRA;

Anselmo Gomes de OLIVEIRA

Editores

\begin{abstract}
A Resolução da Diretoria Colegiada (RDC) $n^{0} 26$, publicada pela Agência Nacional de Vigilância Sanitária (Anvisa) em maio de 2014, trata do registo de medicamentos fitoterápicos e do registro e notificação de produtos tradicionais fitoterápicos (1). Carvalho e Gutierrez (2013), em editorial para Infarma - Ciências Farmacêuticas, anteciparam para o setor regulado, para os profissionais da área da Saúde e para a comunidade científica em geral, os principais enfoques da RDC 26/2014 e dos produtos nela descritos (2). A publicação dessa resolução, bem como da Instrução Normativa de maio de 2014 ( $\operatorname{IN~n}^{0} 20$ ), que traz a lista de medicamentos fitoterápicos de registro simplificado e a lista de produtos tradicionais fitoterápicos de registro simplificado (3), se revelou um marco para a área de fitoterápicos no Brasil e poderá trazer de volta produtos antes utilizados por décadas, mas que estavam fora do mercado por não atenderem às normas de registro anteriores.
\end{abstract}

Contudo, o fato de serem considerados seguros em razão de seu uso tradicional, não significa que efeitos colaterais ou tóxicos, interações com fármacos, com outros fitoterápicos ou mesmo com alimentos não possam ocorrer. Ainda, a subnotificação desses efeitos é um fato incontestável, seja pelo fato de sua ocorrência geralmente não ser atribuída ao fitoterápico (“é natural, não faz mal”), seja pela própria ausência de notificação do evento ao serviço de farmacovigilância, pelos profissionais da saúde.

Assim, a publicação dessas normas tornou evidente, mais uma vez, o papel do profissional farmacêutico na área de Saúde Pública. Considerando que esses produtos são isentos de prescrição médica, a orientação farmacêutica poderá agregar valores imensuráveis na garantia do uso racional e segura desses produtos. Para isso, há necessidade de profissionais capacitados, que possam fornecer aos pacientes toda a orientação necessária, com profissionalismo, competência e dentro de alto padrão ético. Evidentemente isso implica em mudanças, incluindo a formação profissional, a visão que o farmacêutico é o único profissional capacitado para atuar na área de medicamentos nos estabelecimentos de saúde, principalmente em farmácias e drogarias, nas quais o princípio fundamental da interação farmacêutico-usuário do medicamento é mais evidente.

Esse número de Infarma - Ciências Farmacêuticas traz alguns artigos interessantes dentro dessa temática. $\mathrm{O}$ artigo de Castro e Quevedo aponta os anseios de farmacêuti- cos com relação ao aumento de sua capacitação e ampliação de sua área de atuação. Dois outros artigos tratam da farmacovigilância de fitoterápicos: no primeiro, os autores consideram que num período de cerca de 6 meses, uma indústria farmacêutica recebeu cerca de 30 notificações de efeitos não esperados relacionados ao uso de medicamentos fitoterápicos. No segundo, Mazzari e Prieto relatam que, no Brasil, o profissional da saúde não tem atuado de forma marcante e constante nos assuntos de notificação de efeitos adversos relacionados a plantas medicinais e fitoterápicos, o que contribui para aa a lacuna existente nos dados brasileiros no cenário mundial, na área de farmacovigilância desses produtos. Ainda, dentro desse contexto, a interação entre fármacos e alimentos é abordada com grande propriedade por Lombardo e Eserian, interações essas ignoradas em grande parte de suas ocorrências. Contudo, considerando que a culinária brasileira possui como característica a utilização de condimentos e especiarias de forma rica e variada, conhecer os riscos da associação de fármacos com determinados alimentos torna-se um fato muito relevante e mostra a importância da Farmácia Clínica na Saúde Pública.

Dessa forma, esperamos que esse número de Infarma - Ciências Farmacêuticas possa proporcionar uma leitura agradável, reveladora e inspiradora para nossos leitores. Que possa também, dentro dos limites de seu conteúdo, contribuir com o aprimoramento dos diferentes profissionais atuantes na área da saúde, especialmente o farmacêutico, e que também possa estimular mudanças efetivas na atuação profissional.

1) BRASIL. Dispõe sobre o registro de medicamentos fitoterápicos e o registro e a notificação de produtos tradicionais fitoterápicos. Agência Nacional de Vigilância Sanitária. RDC 26/2014 (13 de maio de 2014).

2) Carvalho ACB, Gutierrez IEM. Uma nova classe de fitoterápicos na legislação brasileira: os produtos tradicionais. Infarma - Cienc. Farmac. 2013; 25(2):69-70. DOI: dx.doi.org/10.14450/23189312.v25.e2.a2013.pp69-70

3) BRASIL. Publica a "Lista de medicamentos fitoterápicos de registro simplificado" e a "Lista de produtos tradicionais fitoterápicos de registro simplificado". Agência Nacional de Vigilância Sanitária. IN 2/2014 (13 de maio de 2014). 